\title{
Consideraciones sobre el héroe tardoantiguo: el caso de Apolonio (Hist. Apoll., 12)
}

Considerations on the Late Antiquity Hero: the Case of Apollonius (Hist. Apoll., 12)

\author{
Marcos CARMIGNANI \\ Universidad Nacional de Córdoba \\ Consejo Nacional de Investigaciones Científicas y Técnicas \\ marcoscarmignani@gmail.com
}

\begin{abstract}
RESUMEN: El principal propósito de este artículo es definir las diferencias sustanciales entre el modelo épico-heroico, constituido por Odiseo, y el héroe tardoantiguo, encarnado por Apolonio. Estas diferencias demuestran ciertas claves para entender la configuración heroica tardoantigua, donde el héroe ideal deriva de una relectura cristiana de Virgilio: con la figura de Eneas de fondo, el nuevo héroe de esta época es Cristo. Para esto, se analizarán las coincidencias entre temas paganos y cristianos que se producen en la Historia Apollonii Regis Tyri, específicamente en su capítulo 12, siempre teniendo presente que esta novela reutiliza y transforma algunos motivos homéricos mediados por otras tradiciones. Todo esto responde, según nuestra propuesta, a una sensibilidad integradora tardoantigua y posiblemente cristiana.
\end{abstract}

ABSTRACT: The main intention of this paper is to define the substantial differences between the epic hero, constituted by Odysseus, and the late Antiquity hero, personified by Apollonius of Tyre. These differences show certain keys to understand the late Antiquity hero, where the ideal derives from a Christian rereading of Virgil: the new hero of this time is Christ, with Aeneas as background. In order to do this, I analyze the intersections between pagan and Christian topics that take place in Historia Apollonii Regis Tyri, especially in chapter 12, considering that this novel reuses and transforms some Homeric motifs using other traditions. According to my proposal, this feature responds to a late Antiquity —and possibly Christian — sensibility.

Palabras Clave: Historia Apollonii Regis Tyri, Odisea, Eneida, cristianismo. Key words: Historia Apollonii Regis Tyri, Odyssey, Aeneid, Christianity. RECIBIDO: 12 de agosto de 2013 • ACEPTADO: 29 de abril de 2014.

La Historia Apollonii Regis Tyri (HA) es la tercera novela latina que ha llegado a nosotros, después del Satyricon de Petronio y las Metamorphoses de Apuleyo. Se trata de un relato anónimo que narra las aventuras y vicisitudes de Apolonio, su esposa y su hija Tarsia por el 
Mediterráneo oriental en el período helenístico. La obra se nos presenta en numerosas versiones, la más antigua proviene del siglo V o VI y está escrita en latín, pero muy probablemente deriva de un original compuesto en el siglo III. Por otra parte, existe un debate, hasta hoy irresoluto, acerca de si la $H A$ fue escrita originalmente en griego y luego fue epitomizada y traducida al latín - un texto en su origen pagano y luego cristianizado - o si fue una narración desde su origen compuesta en latín. Sea como fuere, el texto, tal como lo encontramos hoy, se nos presenta en dos recensiones, las llamadas $\mathrm{RA}$ y $\mathrm{RB},{ }^{1}$ de las que tampoco se tienen certezas acerca de sus fechas de composición y de su origen, pero de las que se puede decir que RA presenta un latín más elemental, paratáctico, con una combinación de elementos paganos y cristianos - incluso con algunas reminiscencias bíblicas -, mientras que RB ofrece un texto con un latín más "clásico" y con una mayor coherencia narrativa. Lo que queda absolutamente claro dentro de este cúmulo de problemas es que, debido a las muchas interpolaciones y estratificaciones que se añadieron sucesivamente a lo largo de los siglos, la $H A$ es un verdadero texte vivant. ${ }^{2}$

El objetivo central de nuestra propuesta consiste en definir las diferencias sustanciales entre el modelo épico-heroico, constituido por Odiseo, y el héroe tardoantiguo, encarnado por Apolonio. Estas diferencias evidencian una pista de lectura para poder entender la configuración heroica tardoantigua, donde el héroe ideal deriva de una relectura cristiana de Virgilio: con la figura de Eneas de fondo, el nuevo héroe de esta época es Cristo. Para esto, se analizarán las coincidencias entre temas paganos y cristianos que se producen en la $H A$, específicamente en su capítulo 12 , siempre teniendo presente que esta novela reutiliza y transforma algunos motivos homéricos mediados por otras tradiciones. Todo esto responde, según nuestra propuesta, a una sensibilidad integradora tardoantigua y posiblemente cristiana.

${ }^{1}$ Schmeling 1988 imprime además la RC, conformada por los manuscritos que dependen en igual medida de RA y RB.

${ }^{2}$ Cf. Kortekaas 1984, p. 8. Para diferentes análisis y posiciones acerca de todos estos problemas, cf. principalmente Klebs 1899, Kortekaas 1984, 2004 y 2007, Schmeling 1988, 1996 y 2003, Garbugino 2004 y 2010, y Panayotakis 2012. En español, Puche López 1997 (con muy buena introducción y traducción) y el detallado estudio de la polifonía literaria de la $H A$ realizado por Fernández-Savater 2005. 
En este apartado, nos detendremos en dos aspectos fundamentales para nuestro planteo: la influencia de la épica sobre la novela antigua y las relaciones entre la novela antigua y los motivos cristianos.

1. La influencia del epos sobre la novela es un hecho irrefutable. Tanto la novela griega como la latina, las dos ramas principales de la novelística antigua, le deben mucho a la épica, fundamentalmente a la Odisea. ${ }^{3}$ En el caso de la novela griega, la trama obedece a un modelo narrativo común que le da homogeneidad a pesar de las numerosas variantes: una joven pareja de las mejores familias y de una belleza divina se compromete (o se casa) al comienzo del relato, pero inmediatamente se ve separada por el destino; entonces, sufre una serie de aventuras paralelas derivadas de los topoi del género novela, i. e. viajes, secuestro por piratas, esclavitud, prisión, tormentas, naufragios, juicios en la corte, intentos de seducción por parte de poderosos rivales, etcétera. Finalmente, luego de todas estas peripecias, la pareja se reúne nuevamente, con un final feliz. Este esquema repite, a grandes rasgos, el de la Odisea, donde la separación y reunión de Odiseo y Penélope constituyen el núcleo del poema, puesto que ambos personajes deben superar pruebas y obstáculos. ${ }^{4}$ Asimismo, es muy común que la novela griega cite pasajes homéricos, como en el caso de Caritón (cf. infra), donde se aprecia la integración orgánica de la cita en la prosa y la apropiación de la palabra poética a través de un uso personal..$^{5}$ En el caso de la novela latina, se ha postulado que el Satyricon es tanto una parodia de la Odisea como de la novela erótica griega ${ }^{6}$ debido a que las aventuras pedestres de Encolpio y sus compañeros pueden leerse como el reverso de las protagonizadas por Odiseo o los personajes de las novelas idealistas griegas. Por su parte, las Metamorphoses de Apuleyo, aunque no siguen el esquema de la novela griega, sí se relacionan con el epos, dado que su

${ }^{3}$ Sobre la relación entre épica y novela antigua, la bibliografía es abundantísima. Algunos tratamientos generales pero incisivos pueden encontrarse en Perry 1967, pp. 44-54, Hägg 1983, pp. 110-111, Barchiesi 1988, pp. 341-362, Fusillo 1989, pp. 26-33 y Graverini 2006, pp. 36-39.

${ }^{4}$ Perry 1967, p. 46, describía la novela griega como "latter-day epic", y Reardon 1969, p. 293, agrega: "in a non-heroic world".

${ }^{5}$ Cf. Setaioli 2013.

${ }^{6}$ Para lo primero, cf. Klebs 1889; para lo segundo, cf. Heinze 1899. 
héroe, Lucio, debe atravesar una crisis que le permite comprender con mayor profundidad su propia naturaleza. La transformación de Lucio se origina en una falla de tipo moral y su metamorfosis en asno puede ser vista como un reflejo de su depravación, en el mismo sentido en que el errar de Odiseo o el "exilio" de Aquiles reflejan una censura moral. La transformación final de Lucio en hombre - como la reconciliación de Aquiles con Príamo o la de Odiseo con su familia - es un indicador de su evolución moral. ${ }^{7}$ Sin embargo, a pesar de que el peso de la épica sobre la novela es notable, conviene ser prudente a la hora de analizar las "influencias formativas"8 como una explicación de carácter genético, ya que se corre el riesgo de caer en la parcialidad. Por lo tanto, se impone la necesidad de tomar estas influencias formativas como lo que son: elementos, motivos, caracteres, topoi que contribuyeron a la constitución de la novela. La épica brinda numerosos elementos sin los cuales es difícil pensar en este nuevo género, pero, ciertamente, no hay que exagerar su presencia.

2. La relación entre la novela antigua y los relatos cristianos ya ha sido ampliamente estudiada por la crítica. ${ }^{9}$ Konstan sostiene que "faithfulness, endurance, and a commitment to personal chastity form the basis, in the novels, of a new sense of an autonomous self that is a common denominator between pagan and Christian narratives", ${ }^{10}$ como lo demuestra su estudio del tópico del viaje a un lugar remoto en los relatos cristianos de los Hechos de Jantipo y Polixena y los Hechos de Felipe $\mathrm{y}$ en las novelas griegas. Aunque la trama basada en la separación y reunión de la pareja, que termina con el regreso de los protagonistas al punto original de partida, era particularmente adecuada para ilustrar la lealtad amorosa y la preservación de la fidelidad sexual, Konstan afirma que también podía abarcar relatos de búsqueda y conversión. De esta manera, ejemplifica con el caso de Heliodoro, quien creó una nueva con-

${ }^{7}$ Cf. Toohey 1992, pp. 227-228.

${ }^{8}$ Para este concepto, véase Barchiesi 1988.

${ }^{9}$ Fundamental para este tema, Ramelli 2001, aunque no incluye en su análisis a la HA. Además, Bowersock 1994, y la más reciente compilación de artículos en Futre Pinheiro, Perkins y Pervo 2012. Ramelli 2007 analiza la relación entre el Evangelio de Marcos y el Satyricon, con la interesante conclusión de que "if Petronius and his public had such a knowledge of Christianity, it is plausible that other novelists too knew something about it and alluded to it in their writings" (p. 58).

${ }^{10}$ Konstan 2009, p. 117. 
figuración de la novela que va más allá del desarrollo del lazo amoroso entre los dos protagonistas. ${ }^{11}$

¿Qué ocurre en la $H A$ respecto a estos dos aspectos? Dentro del panorama general de influencia épica sobre la novela antigua, esta obra no es la excepción, puesto que varios motivos temáticos (más que técnicas narrativas) ya aparecían en la Odisea, como veremos más adelante. Además, la $H A$ tiene la peculiaridad de presentar muchas más similitudes con la novela griega que con la latina: no sólo su trama está estrechamente vinculada a la novela idealista griega, sino que carece en absoluto de las complejidades de la novela romana, por lo que un gran crítico la definió como el primer "love-romance" escrito en latín: una ficción ideal griega en latín. ${ }^{12}$ Sin embargo, la $H A$ no se reduce a estas influencias; incluso parece atestiguar la existencia de un estadio en el que este género apuntó a buscar un nuevo espacio de recepción en el ámbito de un público escasamente atraído por la producción literaria tradicional, jugando, quizá, con la vinculación con el mimo y la pantomima. La novela tiene todos los ingredientes para cautivar al gran público, ${ }^{13}$ diríamos hoy, desde una ambientación exótica y sugestiva a los más dispares elementos fantasiosos. No cabe duda de que la $H A$ es el resultado de la acumulación de motivos orales y literarios, cuyo rasgo común es su estructura formulaica, típica de la literatura folclórica y de entretenimiento. Pero, además, la $H A$ presenta otra característica: si la novela griega cita a Homero, la $H A$ cita a Virgilio. ${ }^{14}$ Creemos que este cambio es una de las claves para comprender la transformación del héroe en la novela tardoantigua, puesto que Eneas, pius Aeneas, es el héroe-bisagra buscado por una época signada por la confluencia del paganismo y del cristianismo. El héroe tardoanti-

${ }^{11}$ Konstan 2004-2005 sugiere que el Éxodo judío de Egipto es el modelo del peregrinaje que permite la regeneración moral en un lugar remoto (Etiopía) en las Etiópicas. Se pueden leer tres semejanzas básicas: 1. Calasiris —en su papel de guía-, como Moisés, no alcanza la tierra prometida, 2. Teágenes y Cariclea, mostrándose como hermanos, adoptan la misma estrategia que Abraham y Sara cuando descienden a Egipto (Gen., 12.11-19), y 3. principalmente, la llegada de la pareja de amantes tiene como consecuencia el cambio de costumbres religiosas del pueblo — la abolición del sacrificio humano-, tal como ocurre en la Biblia cuando el cordero reemplaza el sacrificio de Isaac.

${ }^{12}$ Cf. Walsh 1970 , p. 1. Acerca de la relación entre la $H A$ y la novela griega, fundamentales los estudios de Ruiz Montero 1983, pp. 327 ss., y Konstan 1994, pp. 173-182, mientras que para sus vínculos con la novela latina, cf. Schmeling 1996 y 2003.

${ }^{13}$ Para el problema del público lector de la novela griega, cf. Bowie 2003.

${ }^{14}$ Cf. HA, 11, 18, 41 y 42-43. Cf. Carmignani 2014. 
guo no mira más hacia los héroes homéricos, sino que intenta crear un nuevo modelo a través de la fusión de Eneas y Cristo.

En cuanto a la relación entre el cristianismo y la $H A$, además de lo que se ha mencionado en la introducción (cf. § I), debemos decir que, a pesar de los elementos cristianos - presentes debido a una reelaboración que no eliminó los indicios paganos -, no se trata de una verdadera reconversión cultural; de hecho, Schmeling, en su edición Teubner, los elimina por considerarlos interpolaciones. ${ }^{15}$ Como afirma Panayotakis, las nociones de "cristianización" y de "identidad cristiana" son muy complejas y difíciles de explicar en un texto que no tiene una finalidad proselitista ni un mensaje de fe explícitos. Los elementos cristianos que aparecen en la $H A$ son una prueba evidente de que las tradiciones pagana y cristiana no sólo coexisten en la novela "and that their coexistence in the text is not a sign of corruption and degeneration", sino que son la marca de una falta de división taxativa entre lo cristiano y lo pagano, característica de la época. ${ }^{16}$ Este punto es central para nuestro trabajo: la presencia del elemento cristiano permite la reconsideración de la figura del héroe, que adquiere una serie de características que lo distancian del modelo heroico tradicional de Odiseo.

\section{III}

En un artículo de 1990, Holzberg analiza los puntos más destacados de la relación entre la $H A$ y la Odisea. A partir de una postura vinculada con la teoría defendida por Kortekaas, ${ }^{17}$ Holzberg afirma que en la $H A$ se

15 De otra opinión son Kortekaas 1984, p. 106, quien cree que el autor de la RA es cristiano, y Hexter 1988, p. 188, quien comparte esta opinión e incluso agrega que la $H A$ es "profoundly, albeit never explicitly, Christian".

${ }^{16}$ Cf. Panayotakis 2012, p. 8. De todas maneras, creemos acertado el juicio de Ilaria Ramelli, quien afirma, en comunicación personal con el autor y hablando de la relación entre el cristianismo y la $H A$, "I do suspect that a total reassessment is needed on this issue".

${ }^{17}$ Es decir, que el original de la $H A$ es una novela griega pagana de los siglos II o III, de la que RA y RB serían una traducción, una revisión y un epítome al mismo tiempo. Cf. Holzberg 1990, p. 90: "The conclusions to which Kortekaas has come are for the most part so convincing that they must needs form the basis of any future studies (...). Kortekaas, however, quite rightly returns to the older theory propounded by A. Riese, according to which RA stems from a 3rd-century pagan source and RB is an adaptation of RA". 
recuperan todos los temas narrativos importantes de la Odisea, desde la tormenta del final del canto $\mathrm{V}$ hasta el comienzo del relato de Odiseo en el canto IX, transformándolos con otro valor y significado, sobre todo a partir del cambio de papeles y funciones de los personajes. Básicamente, el esquema de analogías sería: Odiseo $>$ Apolonio, Alcínoo $>$ Arquistrates, Nausícaa $>$ filia Archistratis, Arete, quien es reemplazada por varios actores en la $H A$. Asimismo, Holzberg demuestra que hay más paralelos entre ambos textos, por ejemplo con relación a las anagnórisis: Odiseo es identificado como rey por Eumeo, como padre por Telémaco y como esposo por Penélope, del mismo modo que Apolonio es reconocido por el pescador $(H A, 51)$, por Tarsia y por su esposa. Además, ambos héroes se vengan de sus enemigos - Odiseo de los pretendientes y Apolonio del lenón, Estranguilión y Dionisíades - y ambos hacen un resumen de sus aventuras a sus esposas (Od., 23, 310 ss. y $H A, 48) .{ }^{18}$

Es conveniente aclarar, en este punto, que nuestro análisis parte necesariamente de estos presupuestos de Holzberg, pero no sólo examinaremos detenida y minuciosamente los aspectos que no fueron trabajados en el artículo del estudioso alemán, sino que proponemos concentrarnos específicamente en $H A, 12$, que presenta una serie de puntos más que interesantes para la comparación de la Odisea con la $H A$ y para la comprensión del nuevo modelo de héroe que es Apolonio.

$H A, 12$, narra los acontecimientos desde que la nave del héroe naufraga en su viaje de Tarso a Cirene. En ese naufragio murieron todos, excepto Apolonio, que logró llegar a la costa de la Pentápolis aferrado a una tabla; en la playa, desnudo, se dirige a Neptuno reprochándole su destino. En ese momento aparece un anciano vestido con ropas andrajosas ante el que Apolonio se arroja a sus pies, rogándole piedad y ayuda. El pobre viejo lo lleva a su humilde casa, le da de comer y divide en dos su manto, dándole una mitad a Apolonio, mientras le dice que si alguna vez llegara a restablecerse su dignidad, debía acordarse de la ayuda ofrecida a pesar de su pobreza, a lo que Apolonio respondió que si él así no lo hiciera, que otra tempestad cayera sobre su cabeza.

Una de las diferencias fundamentales entre la Odisea y este capítulo de la $H A$ es que el destino de Odiseo está asegurado por la divinidad. En Od., 5, 41-42, Zeus le dice a Hermes:

${ }^{18}$ Cf. Holzberg 1990, p. 98. 


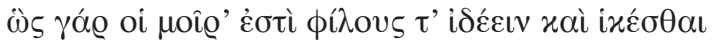

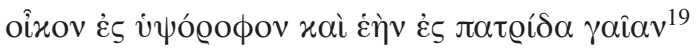

aunque, a pesar de esto, Poseidón lanzará la tempestad sobre la balsa del héroe $(5,286-296)$. En la $H A$ esto no ocurre de la misma manera, no hay una anticipación por parte de la divinidad del destino de Apolonio, pero se deja entrever que un deus está presente para ayudarlo, como sucede en RA, 12, p. 9, 11. 21-23:

illud tamen admoneo te, ut si quando deo favente redditus fueris natalibus tuis, et tu respicias tribulationem paupertatis meae. ${ }^{20}$

Schmeling corrige el texto de RA e imprime favente, pero la lección del manuscrito $\mathrm{P}$ es adveniente. A primera vista, este y otros ablativos absolutos aparecen como desconectados del contexto y parecen ser añadidos tardíos, por lo que Klebs los excluye del texto. ${ }^{21}$ Esta opinión no es compartida por los comentaristas modernos: Kortekaas señala que los ablativos se adecuan perfectamente al contexto y hacen referencia al Dios cristiano, ${ }^{22}$ mientras que Panayotakis afirma que "the religious beliefs underlying a single deus in general, and deo favente in particular, are by no means clear" y concluye que la referencia a una única divinidad no indica interpolación cristiana. Creemos que este tipo de construcciones es una clara muestra de la "coexistencia" de las tradiciones pagana y cristiana en el texto. ${ }^{23}$ Debemos ser muy prudentes con re-

19 Todas las traducciones son nuestras, excepto que se indique lo contrario. "Porque es su destino ver a sus seres queridos y regresar a la casa de alto techo y a la tierra de sus padres".

20 "Pero te lo advierto, si alguna vez, con la ayuda de un dios, fueras restituido a tu linaje, también tú ten en cuenta el sufrimiento de mi pobreza". El texto de la $H A$ corresponde a Schmeling 1988. Se cita de acuerdo con el número de capítulo, página y líneas de esa edición.

${ }^{21}$ Cf. Klebs 1899, p. 190.

22 Kortekaas 2004, p. 22. Para otras expresiones referidas a Dios en singular, cf. caps. 4, 9, 13, 14, 17, 20, 21, 22, 24, 28, 30, 31, 32, 35, 39, 40, 41, 43.

${ }^{23}$ Panayotakis 2012, p. 102. Ante esta interpretación, preferimos traducir deo favente como "con la ayuda de un dios", entendiendo que ese "dios" puede referir a ambas tradiciones. No olvidemos que, como afirma Kortekaas 2007, pp. 53, 278, "Christian authors use the expression more often", "is naturally very frequent in Christian authors like Cyprian, Jerome, Augustine, through to the furthest and latest writings, deep into the Middle Ages". 
lación a la interpretación de los elementos cristianos, por lo que creemos que la expresión deo favente (deo adveniente) no constituye una prueba eficiente de que el destino del héroe está regido por Dios, pero son notables dos hechos: 1 . quien dice estas palabras es el piscator que dividió en dos su manto, repitiendo el gesto cristiano de san Martín de Tours (cf. infra), y 2. lo que dice el pescador se cumplirá y Apolonio regresará para agradecerle (cf. $H A, 51)$.

Otro aspecto donde se perciben discrepancias entre la épica homérica y la $H A$ se vincula con el $x \lambda \varepsilon ́$ os heroico. En $O d ., 5,299-312$, se lee:

$\ddot{\omega} \mu \mathrm{ol} \dot{\varepsilon} \gamma \omega \grave{\omega} \delta \varepsilon \iota \lambda \hat{\varsigma}$ [...]

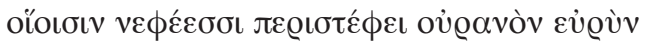

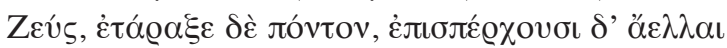

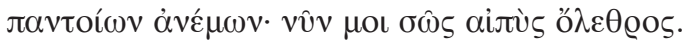

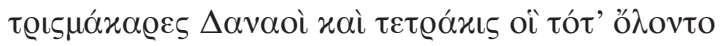

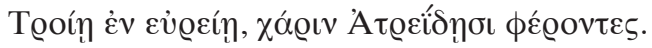

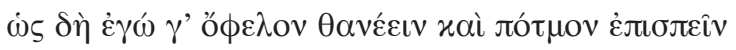

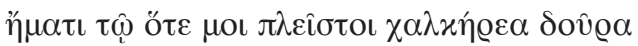

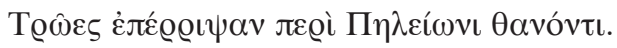

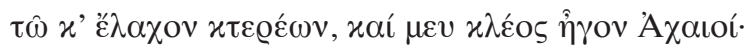

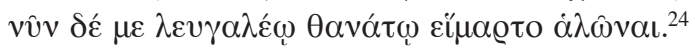

Es llamativo que Odiseo inculpe a Zeus por la tormenta. En Homero, cuando un mortal desconoce la verdad, siempre acusa a Zeus o a alguna divinidad que le parece adecuada (como Paris, que acusa a Atenea en Il., 3, 439). Recién en 6, 326 y 7, 271, Odiseo supone que es Poseidón el culpable de sus males. ${ }^{25}$ En la $H A$, el héroe parece tener muy claro cuál es el culpable, algo típico de la novela, que siempre encuentra el dios perseguidor correcto - como ocurre en la novela griega con Poseidón en Aquiles Tacio $(3,5,4)$ y con Príapo en Petronio-:

24 “¡Pobre de mí! (...) ¡Con qué nubes Zeus ciñe el ancho cielo! Ha trastornado el mar, arrecian ráfagas de toda clase de vientos. Ahora para mí es segura la escarpada muerte ¡Tres y cuatro veces dichosos los dánaos que perecieron en la vasta tierra de Troya llevando contento a los Atridas! Así hubiera yo muerto también y hubiera cumplido mi destino, el día en que multitud de troyanos me arrojaban broncíneas lanzas junto al Pélida muerto. Hubiera tenido honras fúnebres y de los aqueos la gloria: ahora me toca ser presa de una muerte miserable".

${ }^{25}$ Cf. Hainsworth 1997, p. 177. 
o Neptune, rector pelagi, hominum deceptor innocentium, propter hoc me reservasti egenum et pauperem, quod facilius rex crudelissimus Antiochus persequebatur! quo itaque ibo? quam partem petam? vel quis ignoto vitae dabit auxilium? (RA, 12, p. 9, 11. 4-7) ${ }^{26}$

Dos elementos relacionan este pasaje con la Odisea: 1. la referencia explícita a Neptuno implica el paralelismo entre Apolonio y Odiseo, que fue perseguido por Poseidón, y 2. la agonía retórica del náufrago aparece

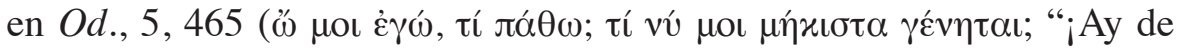
mí, cuánto sufro! ¿Qué me irá a suceder finalmente?”). ${ }^{27}$ Sin embargo, mucho más interesante es lo que se desprende de estas reflexiones: el dolor por perecer de esta manera tiene diferentes motivaciones. El hecho de morir insepulto origina preocupaciones lógicas en Odiseo, que tienen que ver con las desagradables consecuencias en la vida del más allá (Il., 23, 69-74 y Od., 11, 51-78), pero mucho peor aún es la desgracia humillante que implicaba, sólo deseable a un enemigo: una tumba ase-

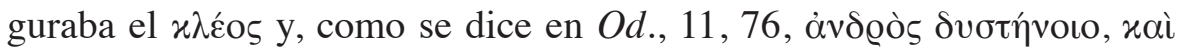

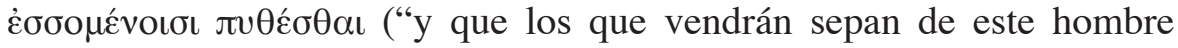

26 “Oh Neptuno, señor del océano, engañador de hombres inocentes, ¿para esto me salvaste necesitado y pobre, para que el crudelísimo rey Antíoco me persiga más fácilmente? ¿Ahora adónde iré? ¿Qué dirección tomaré? ¿Quién querrá ayudar a un desconocido?". En RB, 12, p. 52, 11. 9-14, encontramos una versión diferente del lamento: “o Neptune, praedator maris, fraudator hominum, innocentium deceptor, tabularum latro, Antiocho rege crudelior, utinam animam abstulisses meam! cui me solum reliquisti, egenum et miserum et impio naufragum? facilius rex crudelissimus persequetur! quo itaque pergam? quam partem petam? quis ignotus ignoto auxilium dabit?". ("Oh Neptuno, depredador del mar, engañador de inocentes, ladrón de las tablas, más cruel que el rey Antíoco, ¡ojalá arrancaras mi alma! ¿Para qué me dejaste solo, necesitado y desgraciado y náufrago, impiadosamente? ¿Adónde me dirigiré? ¿Qué dirección tomaré? ¿Qué desconocido querrá ayudar a un desconocido?"). Las diferencias entre RA y RB han sido mencionadas por Kortekaas 2007, pp. 158 ss. Pero, además, es evidente que la amplificación que sufre el pasaje en RB sirve para una caracterización más profunda e intertextual del personaje: utinam animam abstulisses meam recuerda los lamentos de los héroes épicos y novelescos en esta situación (cf. Verg., Aen., 1, 98). Por su parte, Holzberg 1990, a partir de su consideración del tratamiento de la ira de Neptuno que realiza RB en este pasaje, afirma que RB es más fiel que RA al momento de vertir el original griego, y conjetura que posiblemente el motivo de la ira divina haya estado en el original griego: "it would not be unreasonable to conclude that the ire motif was dropped from the Apollonius novel during abridgment" (p. 99). Presume que el responsable de esto es "the Christian author of the surviving Latin Historia Apollonii" (p. 100).

${ }^{27}$ Cf. Panayotakis 2012, pp. 187, 189. 
desgraciado"). ${ }^{28}$ En la $H A$ esta connotación de la fama post mortem está ausente. Hay una marcada preocupación en el lamento del héroe por las carencias materiales, por la pobreza en que se halla desde este momento y por el futuro más inmediato. Estas tribulaciones se repiten luego en $H A, 14$, donde Apolonio, acomodado frente al rey para cenar, no come porque llora ante la contemplación del oro y las riquezas del palacio de Arquistrates.

A diferencia de la $H A$, la novela griega manifiesta el deseo de perdurar en la memoria de los hombres. En Caritón, cuando Dionisio trama el engaño contra Quéreas para que este pierda las esperanzas de casarse con Calírroe, Policarmo, ante la desesperación de su amigo, pronuncia un discurso donde manifiesta su voluntad de morir juntos, pero esa muerte debe ser especial:

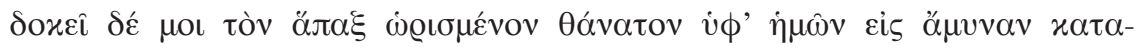

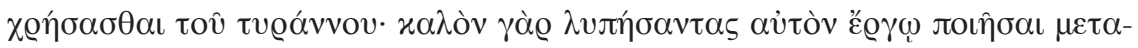

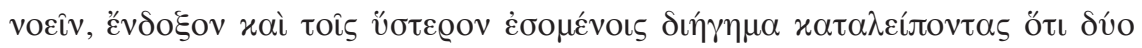

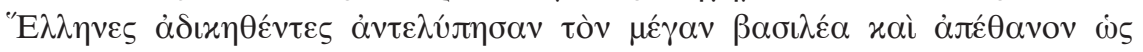

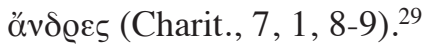

Y más adelante, Quéreas le dice al rey de Egipto, citando a Homero, Il., 22, 304-305 (Charit., 7, 2, 4):

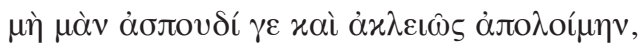

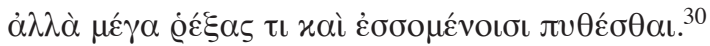

Como afirma Hunter, "the kleos of the fictional characters is the kleos of the fiction", ${ }^{31}$ que confirma la idea de que en la épica $-\mathrm{y}$ en la novela griega - el héroe y el poeta están unidos desde el comienzo en un propósito común, la creación de la fama, $x \lambda \varepsilon \dot{c}$ s, que el héroe logra

\footnotetext{
${ }^{28}$ Cf. Hainsworth 1997, p. 177.

29 "Yo opino que la muerte que al fin hemos decidido debe servir para vengarnos del tirano. Será una acción gloriosa el hacerle arrepentirse causándole un gran daño de hecho, y dejando a la posteridad la historia de dos griegos que, víctimas de una injusticia, devolvieron el golpe al Gran Rey y murieron como hombres". Traducción de Mendoza 1979.

30 "En verdad no voy a morir sin lucha ni gloria, sino haciendo algo grande que conozcan los que vendrán”.

${ }^{31}$ Hunter 1994, p. 1067.
} 
mediante la realización de acciones memorables y el poeta mediante la conmemoración de dichas acciones. No tan casualmente, en la $H A$ la única mención a la posterioridad del relato, a su trascendencia y perdurabilidad, se hace en RB, más consciente del valor literario y estético del relato: ${ }^{32}$

casus suos suorumque ipse descripsit et duo volumina fecit: unum Dianae in templo Ephesiorum, aliud in bibliotheca sua exposuit (RB, 51, p. 82, 11 . 25-27)..$^{33}$

En definitiva, el desinterés por la fama, la gloria, también marca, entonces, una distancia entre Apolonio y Odiseo.

La relación entre Apolonio y Nausícaa define otro momento relevante donde la $H A$ se separa de la tradición homérica. En la Odisea, el encuentro entre Nausícaa y Odiseo es preparado por Homero de una manera soberbia: Atenea se le aparece en sueños a la doncella para instigarla a lavar sus vestidos nupciales, porque ya estaba en edad de matrimonio, y de esta forma encontrar en la orilla del río a Odiseo. Nausícaa y sus doncellas, mientras juegan a la pelota, encuentran a un náufrago horrible, afeado por el sarro marino. La princesa es la única que permanece ante su presencia, porque Atenea le infunde valor, ${ }^{34}$ y Odiseo duda si abrazarle las rodillas, en gesto suplicante, o hablarle de lejos para no irritarla. En su discurso, el héroe la llena de elogios, comparándola con Artemisa, alaba a sus padres y a quien se la lleve como esposa, y agrega (Od., 6, 175-184):

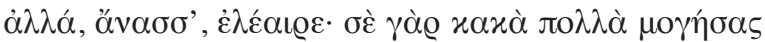

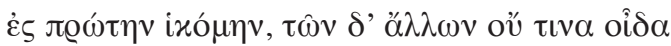

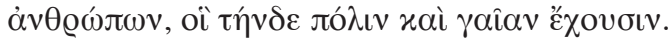

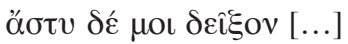

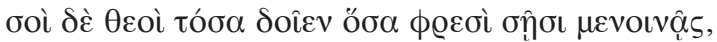

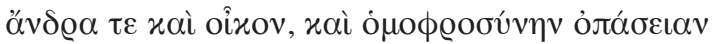

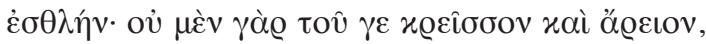

32 Para las diferencias entre ambas recensiones, cf. Carmignani 2014.

33 "El propio Apolonio escribió sus infortunios y los de los suyos e hizo dos copias: una la expuso en el templo de Diana de Éfeso, la otra en su biblioteca”. En Xen. Eph., $5,15,2$, se lee algo similar.

${ }^{34}$ Cf. Od., 6, 137-140. 


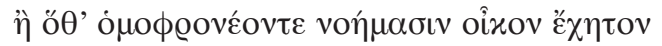

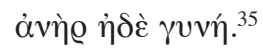

Los versos 181-185 han sido muy discutidos por la crítica, ya que se los considera una amplificación superflua. Pero en $I l ., 13,650$ y $O d ., 2$, 34 y 17, 355 también hay discursos semejantes, aunque son lacónicos, mientras que este es deliberadamente efusivo, manifestando un sentimiento típico del pensamiento arcaico. ${ }^{36}$ Odiseo expresa tres aspectos de la felicidad perfecta para una esposa: marido, casa y concordia. En la $H A$, los acontecimientos son muy diferentes, puesto que la primera persona con la que se encuentra Apolonio es un pescador:

et cum sibimet ipsi increparet, subito anima $<\mathrm{d}>$ vertens vidit quendam grandaevum sago sordido circumdatum. et prosternens se illius ad pedes effusis lacrimis ait: "miserere mei, quicumque es, succurre naufrago et egeno, non humilibus natalibus orto! et ut scias cuius miserearis: ego sum Tyrius Apollonius, patriae meae princeps. audi nunc tragoediam calamitatis meae, qui modo genibus tuis provolutus deprecor vitae auxilium. praesta mihi ut vivam" (RA, 12 , p. 9, 11. 8-14). ${ }^{37}$

El espléndido pasaje introductorio del encuentro entre Odiseo y Nausícaa queda reducido en la $H A$ a esta mínima descripción del encuentro del héroe con el viejo pescador. El narrador remarca la suciedad del manto del anciano (RA sago sordido, RB sordido tribunario), que re-

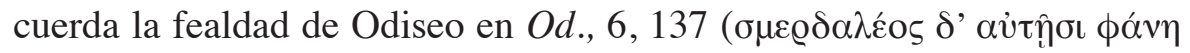

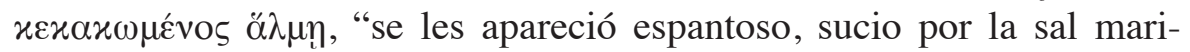
na"). Apolonio resuelve la duda de Odiseo arrojándose a las rodillas del

35 "Pero, reina, apiádate de mí, ya que después de sufrir muchos males eres la primera a quien me acerco, no conozco ningún otro de los hombres que habitan esta ciudad y esta tierra. Muéstrame la ciudad (...). Los dioses te concedan cuanto en tu corazón desees: marido, casa y como compañía la feliz concordia: porque no hay nada mejor ni más precioso que cuando con pensamiento concorde un hombre y una mujer rigen la casa".

${ }^{36}$ Cf. Hainsworth 1997, p. 205.

37 "Y mientras se hacía a sí mismo reproches, de repente, notándolo, vio a un anciano envuelto en un manto sucio, y arrojándose a sus pies le dijo llorando abundantemente: ‘ $¡ T e n$ piedad de mí, quienquiera que seas, socorre a un náufrago y a un necesitado, que no es de origen humilde! Y para que sepas de quién te apiadas: yo soy Apolonio de Tiro, príncipe de mi patria. Escucha ahora la tragedia de mi infortunio, yo, quien ahora arrojado a tus pies, te ruega ayuda para estar vivo. Ayúdame a sobrevivir' ". 
pescador en actitud suplicante, y en su discurso no hay elogios para su salvador, sino una súplica que lo presenta nuevamente como desprovisto de bienes materiales. Y más importante, Apolonio le descubre inmediatamente su identidad al pescador, algo que no hace Odiseo hasta el canto IX. Los motivos del héroe novelesco son aún más evidentes si leemos que en RB se dice que actúa cogente necessitate, es decir, son las circunstancias las que lo obligan a ser suplicante y revelarse como un príncipe, para que el pescador se apiade y lo ayude. En el mundo homérico, Odiseo no necesita de esta sumisión: su orgullo de héroe épico, ayudado por la divinidad, dilata su presentación, como lo hará en Ítaca.

Para profundizar el distanciamiento que se produce con la tradición épica y novelesca en este episodio de la $H A$, es interesante mencionar el análisis de Danese, quien señala la existencia de una estructura narrativa similar entre la llegada a Crotona de Encolpio y sus compañeros en el capítulo 116 del Satyricon petroniano y el retorno del héroe Odiseo al hogar, con la secuencia diegética tempestad-naufragio-salvación milagrosa-ocultamiento de la identidad. ${ }^{38} \mathrm{Si}$ en la Odisea y en el Satyricon ${ }^{39}$ este esquema se repite, en la $H A$ la secuencia diegética tempestad-naufragio-salvación milagrosa-ocultamiento de la identidad no se cumple en su totalidad: como vimos, Apolonio, muy lejos de ocultar su nombre, lo revela inmediatamente al pescador. De esta manera, el encuentro de Apolonio con el piscator rompe este esquema típico de la épica y de los arribos novelescos. ${ }^{40} \mathrm{El}$ hecho de que Apolonio revele su nombre tiene otras dos connotaciones: refuerza el contraste entre linaje-riqueza y

${ }^{38}$ Cf. Danese 1989.

${ }^{39}$ En Petronio, la secuencia tempestad-naufragio-salvación milagrosa se produce en los capítulos 114-115, mientras que el ocultamiento de la identidad - haciendo caso a los consejos de Eumolpo de convertirse en heredipetae en Crotona- comienza en el capítulo 117.

${ }^{40}$ El tópico del pescador también se presenta en Sat., 115, pero su participación es mínima: Hoc opere tandem elaborato casam piscatoriam subimus maerentes, cibisque naufragio corruptis utcumque curati tristissimam exegimus noctem ("Finalizada esta tarea, entramos tristes a la cabaña de un pescador y, después de arreglarnos con la comida arruinada por el naufragio, pasamos una noche tristísima"). Sin embargo, como no podía ser de otra manera en esta novela, los pescadores que más preocupan al lector (y a los personajes) son los del capítulo 114: Procurrere piscatores parvulis expediti navigiis ad praedam rapiendam. Deinde ut aliquos viderunt, qui suas opes defenderent, mutaverunt crudelitatem in auxilium ("unos pescadores se apuraron con sus botes pequeñitos para robar el botín. Después, cuando vieron a algunos que estaban por defender sus pertenencias, cambiaron la crueldad por ayuda"). Indudablemente, el Satyricon es la inversión de toda la tradición del piscator salvador. 
pescador-pobreza, y abre la puerta al futuro gesto de reconocimiento en $H A, 51$.

El encuentro entre Apolonio y el viejo pescador es la marca sustancial de la nueva configuración heroica que presenta la novela. Se sabe que los pescadores hospitalarios son comunes en el mundo del mito (Dánae y Perseo), la comedia (Vidularia y Rudens de Plauto) y la novela (Xen. Ephes., 5, 1, 2; Heliod., 5, 18, 18-22, 24; Sat., 115). En la HA, el piscator adquiere un valor significativo. Como señala Panayotakis, "the character of the 'saviour' fisherman is undoubtedly appropriate in a Christian context too" ${ }^{41}$ En este sentido, es posible asociar la figura del pescador tanto con Nausícaa como con el Buen Samaritano (cf. Vulg., Luc., 10, 33-34). Pero la hospitalidad del senex tiene unas características aún más notables desde el punto de vista cristiano. Ésta es su respuesta ante los ruegos de Apolonio:

itaque piscator ut vidit primam speciem iuvenis, misericordia motus erigit eum et tenens manum eius duxit eum intra tecta parietum domus suae, et posuit epulas quas potuit. et ut plenius misericordiae suae satisfaceret, exuens se tribunarium suum scindit $\{\mathrm{eum}\}$ in duas partes aequaliter et dedit unam iuveni (RA, 12, p. 9, 11. 14-18). ${ }^{42}$

La acción trascendental de la división del manto en dos partes iguales repite el gesto de san Martín de Tours, quien da una parte a un mendigo en Amiens (cf. Sulpicio Severo, Vita san Martini, 3, 1-3), ${ }^{43}$ hecho que

${ }^{41}$ Panayotakis 2012, p. 194.

42 "Cuando el pescador vio la notable figura del joven, conmovido por la misericordia lo levantó y tomándolo de la mano lo llevó dentro de las paredes de su casa y le sirvió la comida que pudo. Y para satisfacer más todavía su misericordia, se quitó su manto y lo dividió en dos partes iguales y le dio una al joven”.

${ }^{43}$ Para un excelente análisis del pasaje y de los términos relacionados, sago (cf. subito anima $<d>$ vertens vidit quendam grandaevum sago sordido circumdatum) y tribunarium, cf. Panayotakis 2009, en oposición a la postura de Kortekaas 2007, p. 162, quien defiende la idea de que el original de la $H A$ es un texto griego perdido. Una de las pruebas de esta hipótesis es, según Kortekaas, el término tribunarium, "a word that clearly points to a Greek origin". Para este crítico, tribunarium (RB) es una traducción del griego

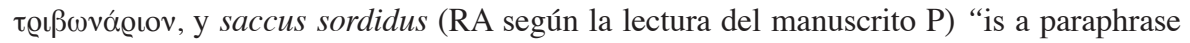
of what is further on called a tribunarium". Por su parte, Panayotakis afirma que tanto tribunarium como sagum son inusuales en el contexto de la vida de un pescador, pero sago es mejor lectura que sacco porque, como tribunarium, alude a "túnicas cortas" y, sobre todo, a la leyenda de san Martín, de modo que la $H A$ dialoga con la biografía. 
remarca que la pobreza y la suciedad exterior del pescador son inversamente proporcionales a su riqueza interior.

El pescador (como Nausícaa) manda, en discurso directo, a Apolonio a la ciudad, le ofrece nuevamente su casa y compartir su trabajo de pescador en el caso de que nadie se apiade de él en la ciudad:

"Tolle hoc quod habeo et vade in civitatem: forsitan invenies, qui tui misereatur. et si non inveneris, huc revertere et mecum laborabis et piscaberis; paupertas quaecumque est sufficiet nobis. illud tamen admoneo te, ut si quando deo favente redditus fueris natalibus tuis, et tu respicias tribulationem paupertatis meae." cui Apollonius ait: "nisi meminero tui, iterum naufragium patiar nec tui similem inveniam!" (RA, 12, p. 9, 11. 19-24). ${ }^{44}$

En este diálogo puede leerse otra pista para la transformación del modelo heroico, si lo comparamos con el único encuentro entre Odiseo y Nausícaa en el palacio de Alcínoo (Od., 8, 461-468):

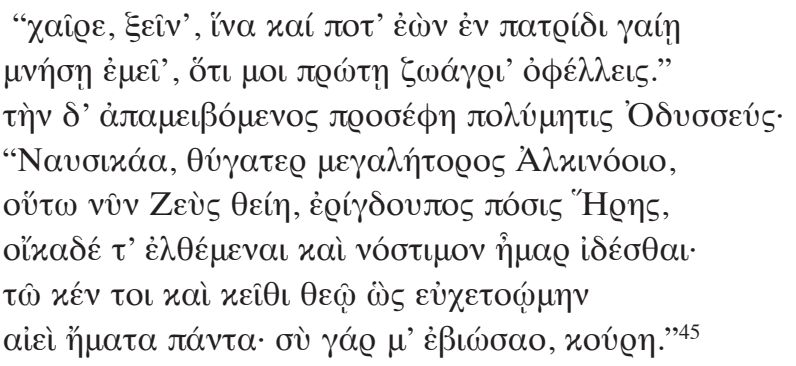

No es casual que en ambos diálogos aparezca el mismo elemento clave, i. e. la memoria de la salvación, representada por los términos $\mu v \eta ́ \sigma \eta$ y respicias/meminero, el deseo por parte del salvador de ser recordado

44 “Toma esto, es todo lo que tengo, y ve a la ciudad: quizá encuentres quien se apiade de ti. Y si no encuentras a nadie, regresa aquí y trabajarás y pescarás conmigo: cualquiera sea esta pobreza, será suficiente para los dos. Pero te lo advierto, si alguna vez, con la ayuda de un dios, fueras restituido a tu linaje, también tú ten en cuenta el sufrimiento de mi pobreza". Y Apolonio le dijo: "Si no me acuerdo de ti, ¡que vuelva a sufrir un naufragio y que no encuentre a alguien como tú!".

45 “Adiós, huésped, para que cuando ya estés en tu tierra paterna te acuerdes de mí, a quien en primer lugar debes tu salvación”. Le respondió Odiseo, el de muchos ardides: "Nausícaa, hija del magnánimo Alcínoo, que así Zeus lo decida, el esposo tonante de Hera, que llegue a casa y vea el día de mi regreso. Allí, ciertamente, te invocaría como a una diosa siempre todos los días, pues tú me diste la vida, muchacha". 
en la posteridad por el náufrago y la promesa del recuerdo por parte de éste. ${ }^{46}$ Es decir, en la Antigüedad tardía se mantiene un rasgo que es, al mismo tiempo, un topos literario (por influencia homérica) y un modo de comportamiento social. Sin embargo, una detenida lectura del pasaje homérico llama la atención. Se cuenta que Odiseo ya se estaba preparando para partir, y éste era el único momento en que la princesa podía dirigirse oportunamente al héroe, es decir, para la doncella es un momento muy significativo, donde quiere enfatizar su marca sobre la supervivencia de Odiseo. Y éste responde acorde al pedido de Nausícaa, o mejor, se expresa demasiado acorde a ese pedido, con una frase, $\theta \varepsilon \hat{\omega}$

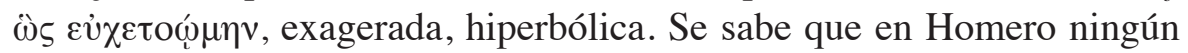
mortal vivo, presente o ausente, es objeto de culto divino: ${ }^{47}$ esa exageración del héroe, de una solemnidad asombrosa, no tendrá la debida repercusión en su relato de viajes de 23, 310 ss., cuando se acordará de Circe y Calipso, pero olvidará de manera flagrante a Nausícaa. Muy diferente actúa Apolonio, que en el capítulo 51 no sólo reconoce al viejo, sino que lo vuelve rico y lo hace conde de por vida:

In illo tempore peractis omnibus iuxta mare deambulat Apollonius, vidit piscatorem illum a quo naufragus susceptus fuerat, qui ei medium suum dedit tribunarium, et iubet famulis suis ut eum comprehenderent et ad suum ducerent palatium. tunc ut vidit se piscator trahi ad palatium, se putavit ad occidendum praeberi. sed ubi ingressus est palatium, Tyrius Apollonius sedens cum sua coniuge eum ad se praecepit adduci et ait ad coniugem: "domina regina et coniunx pudica, hic est paranymphus meus, qui mihi opem tribuit et ut ad te venirem iter ostendit". et intuens eum Apollonius ait: "o benignissime vetule, ego sum Tyrius Apollonius, cui tu dedisti dimidium tuum tribunarium". et donavit ei ducenta sestertia auri, servos et ancillas, vestes et argentum secundum cor suum, et fecit eum comitem, usque dum viveret (RA, 51, p. 43, 11. 11-22). ${ }^{48}$

\footnotetext{
${ }^{46}$ Merry-Riddell 1886, ad loc., comentan que "the trait verifies in one particular way

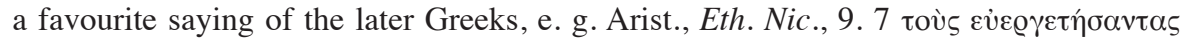

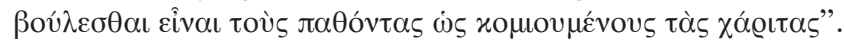

${ }^{47}$ Cf. Hainsworth 1997, p. 292.

48 "En ese tiempo, cuando todo esto ya había terminado, Apolonio paseaba junto al mar, vio a aquel pescador que lo había recibido como náufrago y le había dado la mitad de su manto, y ordenó a sus sirvientes que lo tomaran y lo llevaran a su palacio. Entonces, cuando el pescador vio que lo llevaban al palacio, pensó que sería entregado para su muerte. Pero cuando entró en el palacio, Apolonio de Tiro, sentado con su esposa, ordenó que se lo trajeran y le dijo a su esposa: 'Señora reina y casta esposa, este es mi padrino
} 
El reencuentro entre ambos tiene como modelo el llamado de Jesús a sus primeros discípulos (Vulg., Matth., 4, 18), y en la $H A$ cumple la función de cerrar el episodio que se abrió en el capítulo 12 demostrando que Apolonio no sólo cumple sus promesas, sino que además tiene sentimientos filantrópicos. Asimismo, las palabras del pescador recuerdan el lenguaje bíblico (cf. Vulg., Tob., 5, 25) y la influencia de la novela griega en el concepto de gratitud recíproca (cf. Char., 6, 5, 7; Achill. Tat., 6, 4, 2), con lo cual nuevamente estamos en presencia de este mundo "mixto", pagano y cristiano.

Por último, y a pesar de que no tiene estricta relación con la $H A, 12$ - pero sí con el episodio que allí se inicia-, aludiremos brevemente a que la $H A$ se comporta de manera diferente a la de buena parte de la tradición literaria grecolatina respecto a la actitud del héroe frente a la doncella que lo ayuda y que, inevitablemente, se enamora de él. ${ }^{49}$ Así, encontramos los casos paradigmáticos de Odiseo y Nausícaa (Odisea), Eneas y Dido (Eneida), Teseo y Ariadna (Catulo, 64) ${ }^{50}$ y Jasón y Medea (Apolonio Rodio y Valerio Flaco). Podemos dividir estos casos en dos grandes grupos: 1. aquellos héroes que deciden llevarse consigo a su enamorada y luego la abandonan y 2. aquellos que, luego de haber enamorado con sus encantos a la doncella, deciden seguir su camino sin compañía femenina. Teseo y Jasón corresponden al primer grupo, mientras que Odiseo y Eneas pertenecen al segundo. Sin embargo, el caso de Eneas se presenta como más complejo, porque Dido se enamora del héroe, pero éste también de ella: se trata de un amor correspondido pero imposible por el fatum de Eneas. ${ }^{51}$ No ocurre lo mismo en el caso de Odiseo y Nausícaa:

de bodas, quien me brindó su ayuda y me mostró el camino para llegar a ti'. Y mirándolo, Apolonio le dijo: 'Oh generosísimo viejo, yo soy Apolonio de Tiro, a quien le diste la mitad de tu manto'. Y le dio doscientos mil sestercios de oro, siervos y siervas, vestidos y plata, de acuerdo con su corazón, y lo hizo conde por el resto de su vida". El término

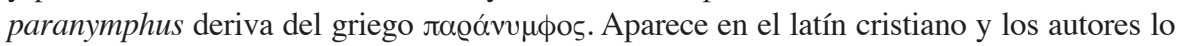
utilizan para describir "either John the Baptist in his role as forerunner of Christ the Bridegroom, or the angels Gabriel and Raphael in their role as "marriage-agents"' (Panayotakis 2012, p. 602), lo que hace que sea perfectamente adecuado para este pasaje de la $H A$.

${ }^{49} \mathrm{El}$ autor desea agradecer especialmente los comentarios de uno de los evaluadores anónimos de Nova Tellus en este punto.

${ }^{50} \mathrm{El}$ único caso de los citados que no constituye una épica sino un epyllion.

${ }^{51}$ Como afirma Cairns 1989, p. 50, hay sólo dos pasajes donde Eneas manifiesta, de alguna manera, su amor por Dido y "neither — and this must be significant - belongs to the period of their love affair". Se trata de Aen., 4, 395 y 6, 455. 
en Virgilio hay claramente una intención trágica en la historia de Dido y Eneas, algo ausente en la relación homérica. Ahora bien, ¿qué lugar ocupa la $H A$ en esta tradición? Apolonio, como Jasón y Teseo, enamora a la hija del rey Arquistrates y se la lleva consigo, pero, a diferencia de aquellos, no abandona a la enamorada, seducida y despechada. Sin embargo, la $H A$ tiene aristas trágicas dado que, en realidad, Apolonio sí deja a su esposa en el mar porque la cree muerta $(H A, 25)$ y luego, al final de la novela, ambos se reencuentran, junto con su hija, para lograr el happy-ending novelesco. Es decir, Apolonio se distancia claramente del modelo odiseico y juega con el modelo virgiliano; a tal punto esto es así que el enamoramiento de la hija del rey se describe con citas virgilianas correspondientes al exordium del libro IV de la Eneida:

Sed "regina gravi iamdudum saucia cura" Apolloni figit in "pectore vultus verba<que>", cantusque memor credit "genus esse deorum". Nec somnum oculis nec "membris dat cura quietem" $\left(H A, 18\right.$, p. 13, 11. 19-21). ${ }^{52}$

Además, como en el modelo virgiliano, el amor es recíproco:

ingens amor fit inter coniuges, mirus affectus, incomparabilis dilectio, inaudita laetitia, quae perpetua caritate complectitur $\left(H A, 23\right.$, p. 16, 11. 29-31). ${ }^{53}$

Vemos, entonces, cómo el héroe Apolonio toma algunas características que lo acercan a Eneas, distanciándolo del modelo homérico de Odiseo, para configurar un héroe diferente, con rasgos propios.

\section{IV}

El núcleo de este trabajo surgió como consecuencia de la lectura del artículo de Holzberg, ya citado, donde se aprecian las semejanzas y diferencias entre la Odisea y la $H A$, sobre todo, en el episodio de Cirene, donde la novela recupera, de alguna manera, la llegada de Odiseo a la

\footnotetext{
52 “Pero 'la reina, herida desde hace tiempo por una grave aflicción', fijó 'en su pecho el rostro y las palabras' de Apolonio, y recordando su canto creyó que 'era de linaje de dioses'. 'La aflicción no da' sueño a sus ojos ni 'reposo a sus miembros'”.

53 "un enorme amor nace entre los cónyuges, un admirable afecto, un incomparable cariño, un inaudito gozo, que los abraza con un amor perpetuo".
} 
tierra de Esqueria. El análisis del crítico alemán es muy interesante y detallado, además de erudito, y enfatiza que "new ways of solving the riddles posed by the $H A$ may be found by attempting to establish structural and thematic links between the original novel and its own literary sources" ${ }^{54}$ Creemos, sin embargo, que esos lazos de los que habla Holzberg también deben tenderse hacia el macro-contexto cultural de la Antigüedad tardía, que implica también la consideración del cristianismo como fenómeno cultural en proceso de expansión. Sin desconocer que es el resultado de la acumulación de motivos no sólo literarios sino también orales, típica de la literatura folclórica y de entretenimiento, tampoco puede obviarse que la $H A$ forma parte de una tradición literaria donde la Eneida juega un papel central - ya dijimos que si la novela griega cita a Homero, la $H A$ cita a Virgilio - y que el cristianismo comenzaba a influir decisivamente sobre la cultura de la época.

Las conclusiones que pueden extraerse de nuestro análisis se vinculan con la consideración de un nuevo modelo heroico que comienza a vislumbrarse en esta época, un modelo que se distancia de manera incontestable de la épica homérica y de su héroe "viajero", Odiseo. A partir de verificar las semejanzas de motivos temáticos entre ambos textos - sobre todo el tema del arribo del héroe a una costa desconocida luego de un naufragio - , intentamos demostrar que la $H A$, para diferenciar a su héroe Apolonio del taimado Odiseo, se nutre de dos tradiciones que triunfarán en la Tardoantigüedad y en el Medioevo: la virgiliana y la cristiana. Creemos que las diferencias entre Odiseo y Apolonio son un indicio de la nueva configuración heroica tardoantigua, donde el héroe ideal no es más el héroe homérico, sino que deriva de una relectura cristiana de Virgilio: el nuevo héroe es Cristo, concebido con la figura de Eneas de fondo, el Salvador inmortal con el héroe mortal troyano en segundo plano. Así como Virgilio concibió a su propio nuevo héroe, pius, con los egocéntricos héroes homéricos de fondo, la Antigüedad tardía pide al lector que comprenda el nuevo significado que se desprende de este nuevo héroe, fruto de la yuxtaposición de las dos tradiciones fundamentales que operaron en la época: la pagana y la cristiana. Es decir, a pesar de que muy probablemente el original de la $H A$ sea un texto griego y de que la cristianización de la novela no es un hecho comprobado, el modelo heroico subyacente está vinculado con las figuras de Eneas y

${ }^{54}$ Holzberg 1990, p. 100. 
Cristo. Éste es el modelo que pervive con mayor fuerza en la Antigüedad tardía y en el Medioevo. ${ }^{55}$

\section{BIBLIOGRAFÍA}

Ediciones, traducciones y comentarios

Garbugino, G., La storia di Apollonio re di Tiro, Alessandria, Edizioni dell'Orso, 2010.

Hainsworth, J. B., Odissea. Volume II. Libri V-VIII, Milano, Lorenzo Valla, 1997. Konstan, D., y M. RoberTs, Historia Apollonii Regis Tyri, Bryn Mawr, Bryn Mawr College, 1985.

KortekaAs, G. A. A., Historia Apollonii Regis Tyri. Prolegomena, text edition of the two principal Latin recensions, bibliography, indices and appendices, Groningen, Bouma's Boekhuis, 1984.

-, The Story of Apollonius, King of Tyre: A Study of its Greek Origin and an Edition of the Two Oldest Latin Recensions, Leiden, Brill, 2004.

_, Commentary on the Historia Apollonii Regis Tyri, Leiden, Brill, 2007.

Mendoza, J., Caritón de Afrodisias. Jenofonte de Éfeso. Fragmentos, Madrid, Gredos, 1979.

Merry, W. W., y J. RidDELl, Homer's Odyssey. Books I-XII, Oxford, Oxford University Press, 1886.

Panayotakis, S., The Story of Apollonius King of Tyre: A Commentary, Berlin, Walter de Gruyter, 2012.

Puche López, M. C., Historia de Apolonio rey de Tiro, Madrid, Akal, 1997.

Schmeling, G., Historia Apollonii Regis Tyri, Leipzig, Teubner, 1988.

\section{Estudios críticos}

BARChIESI, A., "Il romanzo", en F. Montanari (ed.), Da Omero agli Alessandrini. Problemi e figuri della letteratura greca, Roma, Carocci, 1988, pp. 341-362.

Bowersock, G., Fiction as History: Nero to Julian, Berkeley, University of California Press, 1994.

BowIE, E., "The Ancient Readers of the Greek Novels", en G. Schmeling (ed.), The Novel in the Ancient World, 2a ed., Leiden, Brill, 2003, pp. 87-106.

${ }^{55}$ Cf. Schaller 1992, p. 12, quien afirma que la Eneida es la obra excluyente para la tradición épica medieval: "per il Medioevo non esiste un concetto del genere 'epos' come idea-guida, ma la realtà dell'Eneide nella sua monumentale esemplarietà”. Asimismo, la figura del héroe épico medieval aparece como un nudo de confluencias entre dos idiosincrasias culturales, con origen pagano - romano- y anclado en el modelo cristiano (cf. Florio 2002, pp. 53 ss.). 
Cairns, F., Virgil's Augustan Epic, Cambridge, Cambridge University Press, 1989.

Carmignani, M. "La tempestas en la Historia Apollonii Regis Tyri", CFC (L), 34, 2014, pp. 19-36.

DANESE, R., "Il ritorno dell'eroe in patria: quasi una postilla (Petronio, Satyricon 114-115)", StudUrb (B), 62, 1989, pp. 213-220.

Fernández-Savater, M. V., Temas y motivos novelescos. La Historia Apolonii Regis Tyri, Huelva, Universidad de Huelva, 2005.

FLORIO, R., Waltharius. Edición revisada, introducción, comentario y traducción castellana, Madrid, CSIC, 2002.

Fusillo, M., Il romanzo greco. Polifonia ed eros, Venezia, Marsilio, 1989.

Futre Pinheiro, M., M. Perkins y R. Pervo (eds.), The Ancient Novel and Early

Christian and Jewish Narrative: Fictional Intersections, Groningen, Barkhuis

Publishing \& Groningen University Library, 2012.

Garbugino, G., Enigmi della Historia Apollonii Regis Tyri, Bologna, Patròn, 2004.

GraVERINI, L., "Una visione d'insieme", en L. Graverini, W. Keulen y A. Barchiesi

(eds.), Il romanzo antico, Roma, Carocci, 2006, pp. 15-60.

HäGG, T., The Novel in Antiquity, Oxford, Oxford University Press, 1983.

HeInzE, R., "Petron und der griechische Roman", Hermes, 34, 1899, pp. 494-519.

HeXter, R., “Reseña de Kortekaas, Historia Apollonii Regis Tyri”, 1984, Speculum, 63, 1988, pp. 186-189.

HolzBerg, N., "The Historia Apollonii Regis Tyri and the Odyssey”, en H. Hofmann (ed.), Groningen Colloquia on the Novel, vol. 3, Groningen, Egbert Forsten, 1990, pp. 91-101.

HunTER, R., "History and Historicity in Chariton", ANRW, II, 34.2, 1994, pp. 10561086.

Klebs, E., Die Erzählung von Apollonius aus Tyrus. Eine geschichtliche Untersuchung über ihre lateinische Urform und ihre spateren Bearbeitungen, Berlin, G. Reimer, 1899.

—, “Zur Komposition von Petronius' Satirae”, Philologus, 47, 1889, pp. 623-635.

Konstan, D., “Apollonius, King of Tyre, and the Greek Novel”, en J. Tatum (ed.), The Search for the Ancient Novel, Baltimore and London, The Johns Hopkins University Press, 1994, pp. 173-182.

-, "Reunion and Regeneration: Narrative Patterns in Ancient Greek Novels and Christian Acts", en G. Karla (ed.), Fiction on the Fringe: Novelistic Writing in Late Antiquity, Leiden, Brill, 2009, pp. 105-120.

- , "Travel in Heliodorus: Homecoming or Voyage to a Promised Land?", Classica (Revista Brasileira de Estudos Clássicos), 17-18, 2004-2005, pp. 185-192.

Panayotakis, S., "A Fisherman's Cloak and the Literary Texture of the Story of Apollonius, King of Tyre", en F. Gasti (ed.), Il romanzo latino: modelli e tradizione letteraria, Pavia, Collegio Ghislieri, 2009, pp. 125-138.

PERry, B. E., The Ancient Romances: A Literary-Historical Account of their Origins, Berkeley, University of California Press, 1967.

RAMELl, I., I romanzi antichi e il Cristianesimo: contesto e contatti, Madrid, Signifer Libros, 2001. 
-, "The Ancient Novels and the New Testament", Ancient Narrative, 5, 2007, pp. 41-68.

Reardon, B. P., "The Greek Novel”, Phoenix, 23, 1969, pp. 291-309.

Ruiz Montero, C., "La estructura de la Historia Apollonii Regis Tyri", CFC (L), 18, 1983, pp. 291-334.

Schaller, D., "La poesia epica", en G. Cavallo, C. Leonardi y E. Menesto (eds.), Lo Spazio Letterario del Medioevo. 1. Il Medioevo Latino, Roma, Salerno Editrice, 1992, pp. 9-42,

Schmeling, G., "Apollonius of Tyre: Last of the Troublesome Latin Novels", ANRW, II, 34.4, 1996, pp. 3270-3291.

-, "Historia Apollonii Regis Tyri", en G. Schmeling (ed.), The Novel in the Ancient World, $2^{\mathrm{a}}$ ed., Leiden, Brill, 2003, pp. 517-551.

Setaioli, A., "El uso de la cita poética en Petronio y en los demás novelistas antiguos", en M. Carmignani, L. Graverini y B. Lee, Collected Studies on the Roman Novel-Ensayos sobre la novela romana, Córdoba, Brujas, 2013, pp. 97-116.

TooHey, P., Reading Epic: An Introduction to the Ancient Narrative, London, Routledge, 1992.

Walsh, P. G., The Roman Novel. The Satyricon of Petronius and the Metamorphoses of Apuleius, Cambridge, Cambridge University Press, 1970. 
